\title{
Analysis of Traditional Risk Factors of Atherosclerosis and Novel Risk Markers of Inflammation in Coronary Ectasia Can We Solve The Enigma ??
}

Selvaganesh Mariappan ( $\square$ selvapacemaker@yahoo.com )

Velammal Medical College Hospital and Research Institute https://orcid.org/0000-0003-3944-2722

\section{Sivakumar G S}

Madurai Medical College

\section{Saravanan R R}

Madurai Medical College

Satheeshkumar S

Madurai Medical College

Veeramani S R

Madurai Medical College

Balasubramanian S

Madurai Medical College

Arul A.S

Madurai Medical College

Research article

Keywords: Inflammation, atherosclerosis, aneurysm, Coronary ectasia, vascular biology, pathophysiology

Posted Date: September 15th, 2020

DOI: https://doi.org/10.21203/rs.3.rs-71388/v1

License: (1) (1) This work is licensed under a Creative Commons Attribution 4.0 International License. Read Full License 


\section{Abstract}

Background: Coronary artery ectasia(CAE) is speculated as a variant of atherosclerosis. The pathogenesis of CAE remains an enigma. Here in our study, we aimed to elucidate the role of traditional risk factors of atherosclerosis and inflammation in coronary ectasia.

Methods and Results: This comparative study was carried in a tertiary hospital in South India.Patients with coronary artery ectasia and obstructive coronary artery disease were included as cases and controls. Traditional risk factors of atherosclerosis and risk markers of inflammation (neutrophil-lymphocyte ratio(NLR), red cell distribution width (RDW), mean platelet volume (MPV) )were evaluated and comparative analysis was done. Coronary ectasia was observed in $5.6 \%(n=136)$ of the study population. Among those with ectasia,112(82.4\%) patients were having significant obstructive CAD (mixed group), isolated ectasia observed in24 (17.6\%)patients. Isolated ectasia had an inverse association with diabetes mellitus and male:female ratio of (7:1). DM was seen only in $25 \%$ of isolated ectasia groups compared to $42.9 \%, 47.4 \%$ among mixed and obstructive CAD groups respectively $(p<0.05)$. Traditional risk factors were not significantly different between the mixed group and obstructive CAD group. Inflammatory markers were significantly higher among the both ectasia group compared to obstructive CAD group NLR: $3.98 \pm 0.89,3.58 \pm 0.56,2.82 \pm 0.60 p<0.001$. RDW: $12.59 \pm 0.60,12.29 \pm 0.85,12.02 \pm 0.70, p<0.005$. MPV was elevated in all three groups but not much different among groups.

Conclusion: Coronary ectasia commonly seen in association with obstructive CAD, the prevalence of traditional risk factors of atherosclerosis is similar between $C A E+C A D$, obstructive CAD group suggest atherosclerosis as the underlying pathophysiology. Elevated markers of inflammation suggest overlying inflammation on atherosclerosis to be the contributor of ectasia.

\section{Highlights}

- Among the patients with ectasia $82.4 \%$ had associated significant coronary artery diseases.

- Even in the isolated ectasia group significant number of patients had minimal CAD could have been well demonstrated with IVUS not done in our study

- Hence the association between obstructive CAD and CAE , and sharing of risk factors of atherosclerosis suggest underlying mechanism is atherosclerosis

- Significantly elevated inflammatory markers in ectasia group suggest inflammation initiate the medial destruction and Coronary ectasia

\section{Background}

Coronary artery Ectasia (CAE) has been defined as an abnormal dilatation of coronary artery, with luminal diameter exceeding 1.5 times the adjacent normal reference segment. The term “Ectasia” was coined by Lars Bjork in his report of 3 patients with Tetralogy of Fallot . The prevalence of Coronary Artery Ectasia varies form 0.3-12.5\% among patients undergoing diagnostic angiography for varies ischemic syndromes. Highest prevalence reported from India $10 \%-12 \%$ and Pakistan $12.5 \%$.

CAE may occur as an isolated form but most commonly seen in association with obstructive CoronaryArteryDisease. Ectasia is often viewed as a variant form of obstructive Coronary Artery Disease (CAD) and atherosclerosis is considered as a contributing factor in more than half of the cases. Although the association with atherosclerotic CAD is well evident, the relationship between traditional atherosclerotic risk factors and Ectasia remains controversial. Especially its poor correlation with Diabetes mellitus suggested Ectasia is a distinctive form of atherosclerosis characterized by positive remodeling-(Glagovian phenomenon) in contrast to obstructive disease (Negative Remodeling) . .Hemodynamic factors like flow, stretch, shear stress along with inflammatory signals were proposed as the triggers for this abnormal vascular remodeling and postulated as the link between atherosclerosis and CAE in susceptible individual. Multiple studies in this area were showing conflicting evidence, hence the exact pathogenic mechanism still not conclusively defined and in hypothetical stage.

The etiopathogenisis of this entity puzzled the clinician since its discovery, but still there are some unclear undefined areas. Clinical significance remains uncertain and there is no consensus opinion regarding management. Hence further research is essential to solve these enigmas. Being in the region with highest prevalence of $\mathrm{CAE}$, we have planned to analyze the traditional risk factors of atherosclerosis and risk markers of inflammation in patients with Coronary ectasia .

\section{AIMS AND OBJECTIVES :}

1. To assess the prevalence of Coronary Artery Ectasia in patients with CAD

2. To Analysis of Risk factors and clinical presentation of CAE and to compare it with patients having only obstructive CAD

\section{Methods}


Adult patients $>18$ yrs. of age with the diagnosis of CAD , undergoing Angiography in Department of Cardiology Government Rajaji Hospital

\section{CASES:}

Inclusion criteria:

1. Age $\geq 18$ years with diagnosis of CAD ( both Stable Ischemic Heart disease and Acute Coronary Syndrome)

2. Patients having obstructive CAD, Coronary artery Ectasia and/or Coronary artery aneurysm in Coronary angiography

\section{Exclusion criteria:}

1) Age $<18 y r s$

2) Patients already undergone PTCA ,CABG

3) Pre-existing valvular heart disease

4) Pre-existing cardiomyopathies

5) Pre-existing Arrhythmias

7) Concomitant acute or chronic kidney disease

8) Vasculitis (Kawasaki disease ,Takayasu arteritis)

\section{Methods}

From the study population after obtaining informed written consent detailed history were taken .Demographic and personal and health information were collected from the patient. Blood samples were collected for laboratory investigations to assess the conventional and novel risk markers like Neutrophil Lymphocyte Ratio (NLR)Mean platelet volume( MPV) ,Red Cell Distribution width (RDW)

\section{Definition of risk factors.}

Diabetes Mellitus (DM):

Diabetes Mellitus was diagnosed

1. If a patient is already on oral hypoglycemic drugs or on Insulin therapy

2. If a patient has symptoms of DM

Plus

Random Blood sugar of $>200 \mathrm{mg} / \mathrm{dl}$ or

Fasting blood sugar $>126 \mathrm{mg} \%$

Systemic Hypertension :

A patient was diagnosed to have hypertension

1. If he is on antihypertensive therapy

2. If his $\mathrm{BP}$ is $>140 / 90 \mathrm{~mm}$ of $\mathrm{Hg}$ on presentation and on repeat recording

(>2 occasions)

\section{Lipid abnormality:}

If a patient has

1. Elevated LowDensityLipoprotein(LDL) cholesterol $>100 \mathrm{mg} \%$

2. High Triglycerides (TGL) >150 mg\% 
3. HighDensityLipoprotein (HDL) cholesterol < $35 \mathrm{mg} / \mathrm{dl}$

Any patient with Body Mass Index $(\mathrm{BMI})>30 \mathrm{~kg} / \mathrm{m}^{2}$ was labelled as obese

Definition of Acute Coronary Syndrome :

Myocardial infarction (MI)was defined as per Universal definition of MI [i] Diagnosis of Unstable angina was made if a patient fulfil any of the following criteria [ii]

\section{Coronary_Angiography:}

After obtaining an informed written Coronary angiography was done through either right femoral artery or right radial artery approach after sterile aseptic precaution under local anaesthesia using Judkins right and left (JR, JL) coronary catheter . 4 or 5 views for LAD( RAO caudal , AP caudal ,AP cranial ,LAO caudal ,LAO cranial) and 2 or 3views for RCA LAO ,AP cranial LAO cranial were recorded .The films were reviewed by junior resident and findings were confirmed by experienced interventional cardiologist

\section{Definition of Ectasia :}

In our study we followed the definition used in CASS registry abnormal dilatation of coronary artery, with luminal diameter exceeding 1.5 times the adjacent normal reference segment. If no adjacent normal segment could be identified, the mean diameters of the coronary segments in a control group without heart disease served as normal values."

\section{Definition of obstructive CAD in angiogram:}

Obstructive CAD was diagnosed if a patient had $>50 \%$ loss of luminal diameter compared to the reference normal segment.

\section{Definition of Groups:}

According to the angiography patients were categorized into three groups Group A = Isolated Ectasia patients having Ectasia without any evidence of significant obstruction in coronary artery ( $>50 \%)$, Group B Mixed CAE + CAD group Patients with Ectasia and also having significant obstruction in any of the coronaries .Group $\mathrm{C}=$ Pure CAD group patients having only CAD without evidence of CAE

Patients were treated according to the guideline given by American College of Cardiology / American Heart Association . Left ventricular systolic function was recoded with Philips IE 33 echocardiography machine. Clinical events LVF ,in hospital mortality were recorded . Outcome data during follow up were collected specifically regarding the Unstable angina ,MI mortality and recoded for analysis

\section{Stastical Analysis;}

Continuous variables were analyzed with Mean \pm SD (BMI, Lipid parameters, age) . Categorical variables sex ,DM hypertension ,vessel involved outcome ) were described with number \& percentage .Chi Square test used to assess the significance P value $<0.05$ were considered as stastically significant.

\section{Results}

\section{Prevalence:}

Totally 2434 patients undergone coronary angiogram during the study period with the suspicion of Coronary Artery Disease (Chronic Stable Angina ,ACS) Of those 1966 patients was eligible for our study . Coronary ectasia was found in 136 (5.6\%) patients of whom 24 (1.0\%) patients were diagnosed to have isolated ectasia (isolated ectasia group) without evidence of significant obstructive coronary disease and 112 (4.6\%) (CAE+CAD group) patients with ectasia were having associated with obstructive CAD . Remaining1830 patients were having pure obstructive CAD (CAD group)(75.2\%).Baseline characters have been tabulated in Table 1. Isolated ectasia (dilated coronaropathy) contributes to $17.6 \%(\mathrm{n}=24$ )of coronary ectasia ,remaining $82.4 \%$ had associated obstructive CAD $(n=112)$.

\section{Age \& Sex:}

Mean age of the population in isolated ectasia is significantly lower $(44 \pm 8.6$ Vs $54.32 \pm 8.72$ Vs $56 \pm 7.8 \mathrm{P}<0.001)$ compared to mixed CAE $+\mathrm{CAD}$ group and isolated CAD. Sex distribution showed male predominance in all the groups .the proportion among total ectactic population is M: $\mathrm{F}$ 3.1:1.Significant male dominance was noted in Isolated ectasia group ( $7: 1 \mathrm{p}$ value $<0.001)$. But when comparing total ectasia group ( $\mathrm{n}=136)$ to isolated CAD the male dominance nullified indicated that male sex is a significant risk factor for Dilated coronaropathy(Isolated ectasia). But male sex is not a significant risk factor mixed ectasia group (CAE+CAD) when comparing with isolated CAD group the male(2.7:1 Vs 2.5:1 P value NS) dominance is due to high incidence of CAD among males . 


\section{Smoking:}

Among the isolated ectasia group $62.5 \%(n=15)$ patients were smokers whereas in mixed and isolated CAD group smokers were $53.6 \%$ $(n=60), 51.6 \%(n=944 / 1830)$ respectively.

\section{Other Conventional Risk Factors :}

Diabetes Mellitus was observed in 25\% ( $n=6 / 24$ ) of patients with isolated ectasia In mixed group DM was seen in 48/112 patients and in pure CAD $47.4 \%$ of patients were having DM. Prevalence DM is similar in mixed group and pure CAD But in isolated ectasia prevalence of significantly lower when compared to other groups indicating the inverse association between Diabetes mellitus \& isolated ectasia, not in mixed group

Systemic Hypertension was found in 33.3\% ( $n=8 / 24$ ) of isolated ectasia group whereas in mixed and pure CAD group it was $47.3 \%$ ( $n=53 / 112$ ) and $49.4 \%$ respectively . Five among 24 isolated ectasia patients $(20.8 \%)$ were obese with the BMl of $>30$, in mixed group $23.2 \%$ were obese in pure CAD $22.6 \%$ were obese .Mean LDL was $105 \pm 22.68 \mathrm{mg} \%$ in isolated ectasia patients with LDL > $100 \mathrm{mg} \%$ was observed in $29.2 \%$ of the patients . In mixed and pure CAD group mean LDL cholesterol was $104.9 \pm 19.8,108 \pm 16.7 \mathrm{mg} \%$ respectively with high LDL was noted among $36.6 \%$, and $37.1 \%$ of the patients in these group the difference was not significant .Similarly HDL cholesterol was low in half the isolated ectasia group $54.1 \%$ but the difference between the groups were not statistically significant, the mean among different group was $37.9 \pm-8$ in isolated ectasia patients $36.19 \pm 7.13 \& 37.52 \pm 6.9$ in mixed group and pure CAD population. Significantly less number of people in isolated ectasia were having hypertriglyceridemia but the mean level was not statistically significant across the 3 groups .

\section{Novel Risk Markers :}

Mean Neutrophil count was significantly higher among isolated ectasia group and in CAE+CAD group compared to pure CAD group 5.986 \pm 1.497 Vs 6.019 \pm 1030 Vs 4.480 \pm 1.230 ( $P$ Value $<0.001$ ). In addition neutrophil to lymphocyte ratio also significantly higher $(P$ Value $<0.001)$ in Isolated and mixed ectasia group $3.98 \pm 0.89 \& 3.58 \pm 0.56$ when compared to pure CAD group $2.82 \pm 0.60$. Role of Platelet activation was assessed by measuring MPV difference between the mean of MPV was not significant among the three groups $9.94 \pm 1.56 \mathrm{Vs} 9.56 \pm 1.06 \mathrm{Vs} 9.70 \pm 1.36$ $(P=0.379)$. Similarly Red cell Distribution Width also measured to assess the inflammatory component. RDW in patients with isolated ectasia is significantly elevated $12.59 \pm 0.60$ Vs $12.09 \pm 0.85$ Vs $12.12 \pm 0.70 P<0.005$..

\section{Discussion}

In our study conducted in South India ,totally 136 among 2434 patients with clinical suspicion CAD had coronary ectasia .So the prevalence of ectasia was $5.6 \%$ Prevalence of isolated ectasia was $1 \%(n=24)$. In the literature prevalence of ectasia varies from $0.3 \%-12.5 \%$. The highest prevalence reported in Indian subcontinent (India -10-12\%, Pakistan 12.5\%). Except few studies majority reported prevalence < 5\% ( CASS registry-4.9\%[i] Spain-3.39\%, Greek 2.7\% ) Similarly Harikrishnan et al from Kerala[ii] -South India reported 4.5\% among 3200 angiogram. The prevalence isolated ectasia without significant coronary stenosis (dilated coronaropathy) in our study was $1 \%(n=24)$. Harikrishnan et al reported prevalence of $0.6 \%$ Nyamu et al in their dedicated study on isolated ectasia reported a prevalence of $1.9 \%$ among 6938 angiogram[iii] .

\section{Association with CAD:}

Isolated ectasia (dilated coronaropathy) was observed in $17.6 \%(n=24)$ of all ectasia remaining $82.4 \%$ had associated obstructive CAD ( $\mathrm{n}=112)$. Pinar Bermúdez et al ${ }^{5}$ in their study found that $77.6 \%$ of the CAE patients had associated stenosis CSP Lam et al from Singapore observed $82 \%$ of their patients with CAE had associated obstructive CAD[iv] . Several studies reported similar observation and P. Ramappa, et al in their excellent review reported found $>50 \%$ of patients with ectasia in the literature had underlying stenotic atherosclerosis[v] . Histologic findings in autopsy cases reveal extensive atherosclerotic changes and destruction of the media of the vessel wall[vi]. In view of its significant association with atherosclerosis CASS registry concluded Coronary Ectasia as a variant of atherosclerosis.

\section{Isolated ectasia - Is it a right terminology???}

By definition isolated ectasia excludes atherosclerosis, connective tissue valvular and congenital disease. But Ge et al[vii] in a IVUS based study found that atheroma burden even inside the ectactic segment. Similarly in our angiographic study $40 \%$ of patients with isolated ectasia had non-significant stenosis with $30-40 \%$ narrowing of lumen. Conventional coronary angiogram is less sensitive in detecting narrowing less than $30 \%$, with ectasia luminal loss may also be underestimated . Hence it does not recognize minimal atherosclerosis, require IVUS to pick up this minimal atheroma. So the terminology of isolated ectasia itself to be questioned without coronary imaging (IVUS) especially in adults

\section{Traditional Risk factors \& CAE:}

Patients in the isolated ectasia group were younger than other groups ( $44 \pm 8.6$ Vs $54.32 \pm 8.72$ Vs $56 \pm 7.8 \mathrm{P}<0.001)$.This finding is consistent with the finding of some previous studies. Gender distribution showed male predominance in all the groups .the proportion among total ectactic 
population is M:F 3.1:1.Significant male dominance was noted in Isolated ectasia group (7:1 p value $<0.001)$. But when comparing total ectasia group $(n=136)$ to pure CAD the male dominance nullified indicated that male sex is a significant risk factor for Dilated coronaropathy(Isolated ectasia). But male sex is not a significant risk factor mixed ectasia group (CAE+CAD) when comparing with isolated CAD group the male(2.7:1 Vs 2.5:1 $\mathrm{P}$ value NS) dominance is due to high incidence of CAD among males. Male dominance(M:F 2-3:1) was noted in some previous studies also especially in isolated ectasia group but no statistical significance was found between CAD and CAE group. Some authors attributed that the difference is due to lower incidence of CAD among women but G G Hartnell[viii] reported significant male dominance despite the allowance given for lower incidence of CAD in females.

Among the traditional risk factors, Diabetes mellitus has unique position with ectasia, Giannoglou GD et al [ix] Williams SB[x] et al reported negative association between ectasia and diabetes mellitus. After a metaanalysis Huang et al concluded that DM has inverse association with CAE and act as a protective factor too[xi]. . In our study we found a similar inverse relation between isolated ectasia and DM 6 (25\%) vs $48(42.9 \%)$ vs $868(47.4 \%)<0.05$ with significantly lower incidence of DM in isolated ectasia group compared mixed and pure CAD group. But there was no difference between mixed and pure CAD group which is contradictory to the meta-analysis QJ Haung .,et al. Negative association between DM and ectasia observed only in patients with isolated Ectasia vs others . Other traditional risk factors like LDL ,HDL does not different among all the three groups. But people with isolated ectasia had significantly lower BMI compared to others. Which we suspected probably due to less incidence of Diabetes and younger hard working manual labourers in ectasia group .

Isolated ectasia is unique observed in smoking, younger population having significantly low prevalence of DM. But the ectasia coexisting with obstructive CAD (Mixed)does not differ much from pure obstructive CAD.

\section{Novel Risk markers :}

Evidence for the link between inflammation and CAE becoming strong day by day. To evaluate the inflammatory hypothesis with underlying atherosclerosis as possible pathogenic mechanism of coronary artery ectasia we assessed the inexpensive markers of inflammation. In line with previous observation our study also showed high neutrophil count and NLR in CAE group compared to pure CAD group. Mean Neutrophil in CAE vs mixed CAE +CAD vs pure CAD is $5.986 \pm 1.497$ Vs $6.019 \pm 1030$ Vs $4.480 \pm 1.230$ ( $P$ Value $<0.001$ ) NLR is $3.98 \pm 0.89 \& 3.58 \pm 0.56$ vs $2.82 \pm 0.60$. . Elevated markers of neutrophil mediated inflammation have already been demonstrated in by CAE Turhan $\mathrm{H}$ etal, and Li JJ et al[xii]. Atherosclerosis primarily intimal disease, CAE differs histologically from obstructive disease by significant tunica media destruction. This high neutrophil mediated inflammatory activity have been proposed as the explanation for CAE in obstructive CAD (mixed group). MPV platelet volume a marker of hyperactive platelet found to be higher among CAE compared to healthy control but similar between CAE and CAD group .Here in our study MPV was not significantly different between groups. MPV an indicator of platelet activity is not different among the groups, suggest that platelet appears to be equally active in CAD and Ectasia group. But here we did not compare with the normal control group , so we cannot underestimate the role of MPV. Another indirect marker of inflammation is RDW which was significantly elevated among isolated CAE compared to CAD similar to report by Xiao-Lin Li et al[xiii]. Among the novel easily available markers of inflammation, RDW, NLR, significantly elevated in isolated ectasia, mixed group(NLR ) supporting the inflammatory hypothesis.

\section{Summary \& Conclusion}

1. Association of CAE with obstructive CAD (82.4\%) and similar risk profile even DM in both mixed CAE+ CAD and pure CAD group, supports the hypothesis that underlying pathogenesis in CAE ,CAD are same which is atherosclerosis. Even in isolated ectasia group about $40 \%$ had minimal stenosis $<40 \%$ (Unpublished Data) further strengthen the relation with atherosclerosis. Histopathologically also ectasia resembles atherosclerosis except for medial degeneration.

2. But why some people develop CAE others not? Inflammatory hypothesis might be the possible answer. Probably genetic predisposition along with endothelium mediated vasodilatation may play some role. Excessive expansive remodeling as result of lytic enzymes (myeloperoxidase,Elastase) released by the neutrophil may be the explanation for isolated ectasia.

3. By recapitulating Glagovian phenomenon and with current knowledge, we concur with the hypothesis that "chronobiologically ectasia may be an early stage expression of atherosclerosis with dominant neutrophil mediated inflammatory phenomenon. Obstructive disease is an expression of late stage and CAE + CAD could be an intermediate transitory stage ${ }^{\prime}$ and this need larger properly planned study for comprehensive evaluation(including vascular morphology assessment with HPE ).

4. As some studies showing association of CAE to Abdominal aortic aneurysm, varicose veins, E Yetkin, S Ozturk suggested CAE as a part of systemic dilating vasculopathy, a new hypothesis needs further research.

\section{Limitation :}

1. The number of population in isolated group is very less

2. Other inflammatory markers hs CRP, were not assessed 
3. Healthy controls were not selected for comparison

\section{Abbreviations}

\begin{tabular}{cll} 
S.No & Abbreviation & Full Term \\
\hline 1. & CAE & Coronary Artery Ectasia \\
\hline 2. & CAD & Coronary Artery Disease \\
\hline 3. & NLR & Neutrophil Lymphocyte Ratio \\
\hline 4 & MPV & Mean platelet volume \\
\hline 5. & RDW & Red Cell Distribution width \\
\hline 6. & IVUS & Intra Vascular Ultra Sound
\end{tabular}

\section{Declarations}

Ethical Approval: Approval obtained from the

Institutional Ethical committee Madurai Medical college

Consent For Publication : Obtained and available

Availability of data \& material : The datasets used and/or analysed during the current study are available from the corresponding author on reasonable request

Source of Funding: None

Competing interests : None

Authors contribution : AS A, BS \&SM formulated

ideas

SGS SRR \& VSR analyzed angiogram

SM collected the data

SS \& SM did the statistical work

ACKNOWLEDGEMENT : None

\section{References}

1. Bjork L Ectasia of Coronary Arteries 1966;87:33-34

2. Oliveros RA, Falsetti HL, Carroll RJ, Heinle RA, Ryan GF. Atherosclerotic coronary artery aneurysm report of five cases and a review of the literature. Arch Intern Med 1974; 134: 1072-6.

3. Muhammad Nawaz Lashari, Khalid Bhati, et al Frequency of coronary artery dilatation aneurysm and ectasia - in patients undergoing coronary arteriography PJC 2013; 24: 17-22

4. Sharma SN, Kaul U, Sharma S, Wasir HS, Manchanda SC, Bahl VK, Talwar KK, Rajani M, Bhatia ML. Coronary arteriographic profile in young and old Indian patients with ischaemic heart disease: a comparative study. Indian Heart J 1990;42:365-69

5. Eduardo Pinar Bermúdez, Ramón López Palop, Íñigo Lozano Martíne Luengas,Rocío Cortés Sánchez, Pilar Carrillo Sáez, Raúl RodrígueCarreras, Francisco Picó Aracil and Mariano Valdés Chávarr Coronary ectasia: Prevalence and clinical and angiographic characteristics. Rev Esp Cardiol 2003;56(5):473-479

6. Ertan Yetkin, MD and Johannes Waltenberger, MD PhD Novel insights into an old controversy Is coronary artery ectasia a variant of coronary atherosclerosis? Clin Res Cardiol. 2007 Jun; 96(6): 331-339

7. Aristides E. Androulakis, MD, Georgios K. Andrikopoulos, MD, Athanasios N. Kartalis, MD, Pavlos N. Stougiannos, MD, Andreas A. Katsaros, MD,Dimitrios N. Syrogiannidis, MD, Eustratios N. Tapanlis, MD, Christodoulos Stefanadis, MD, and loannis E. Kallikazaros, MD Relation of coronary artery ectasia to diabetes mellitus. Am J Cardiol. 2004 93:1165- 1167

Page $7 / 13$ 
8. Konstantinos C Koskinas, Charles L. Feldman, Yiannis S. Chatzizisis, Ahmet U. Coskun, Michael Jonas, Charles Maynard, Aaron Baker, Michail I Papafaklis, Elazer R. Edelman, Peter H. Stone Natural History of Experimental Coronary Atherosclerosis a Vascular Remodeling In Relation to Endothelial Shear Stress: A Serial, In Vivo Intravascular Ultrasound Study Circulation. 2010 May 18; 121(19): 2092-2101

9. Lale Tokgozoglu, Oktay Ergene, Ozan Kinay, Cem Nazli, Gülsen Hascelik \& Yesim Hoscan (2004) Plasma interleukin-6 levels are increased in Coronaryarteryectasia, ActaCardiologica, 59:5, 515-519, DOI: 10.2143/AC.59.5.2005226

10. K Thygesen, Joseph S. Alpert, Allan S. Jaffe, et al Third universal definition of Myocardial Infarction Circulation. 2012;126:2020-2035

11. Braunwald E. Unstable angina: a classification. Circulation 1989;80:410 4 (14)

12. CASS Principal Investigators and their Associates. Coronary Artery Surgery Study (CASS): a randomized trial of coronary artery bypass surgery, survival data. Circulation 1983; 68:939-50.

13. Harikrishnan S, Sunder KR, Tharakan J, Titus T, Bhat A, Sivasankaran S, Francis B Coronary artery ectasia: Angiographic, clinical profile and follow-up Indian Heart J 2000;52(5):547-553

14. Peter Nyamu, MMed, Mullasari S Ajit, Peter K Joseph The Prevalence and Clinical Profile of Angiographic Coronary Ectasia Asian Cardiovasc Thorac Ann 2003;11:122-6

15. Lam CSP \& Ho, Kheng-Thye.,. Coronary artery ectasia: A ten-year experience in a tertiary hospital in Singapore. Ann Acad Med Singapor 2004;33:419-422

16. P.Ramappa,M.D.,A.Kottam,M.D.,H.Kuivanemi,M.D.,PH.D., D.Thatai, M.D. Coronary Artery Ectasia - Is It Time for a Reappraisal? Clin. Cardiol. (2007)30, 214-217

17. Turhan H, Erbay AR, Yasar AS, Aksoy Y, Bicer A, Yetkin G, Yetkin E: Plasma soluble adhesion molecules; intercellular adhesion molecule-1, vascular cell adhesion molecule-1 and E-selectin levels in patients with isolated coronary artery ectasia. Coron Artery Dis 2005;16(1):45-50.

18. JunboGeMDFengqiLiuMDPeterKearneyMRCPIGünterGörgeMD MichaelHaudeMDDietrichBaumgartMDMahmoudAshryMD RaimundErbelMD. Intravascular ultrasound approach to the diagnosis of coronary artery aneurysms Am Heart J 1995 130 765-771

19. Hartnell GG, Parnell BM, Pridie RB: Coronary artery ectasia. Its prevalence and clinical significance in 4,993 patients. Br Heart J 1985;54(4):392-395

20. George D. Giannoglou, MD, PhD, Antonios P. Antoniadis, MD, MSc, Yiannis S. Chatzizisis,MD, MSc, Efthalia Damvopoulou, MD, MSc,GeorgeE Parcharidis, MD, PhD, and George E. Louridas, MD, PhD Prevalence of Ectasia in Human Coronary Arteries in Patients in Northern Greece Referred for Coronary Angiography.Am J Cardiol 2006 98:314-318

21. Williams SB, Cusco JA, Roddy MA, Johnstone MT, CreagerMA. Impaired nitric oxide-mediated vasodilation in patients with non-insulindependent diabetes mellitus. J Am Coll Cardiol 1996; 27:567-74.

22. Huang QJ, Liu J, Chen MH, Li JJ Relation of diabetes to coronary artery ectasia: A meta-analysis study. Anadolu Kardiyol Derg. 2014 Jun;14(4):322-7

23. Li JJ, Nie SP, Qian XW, Zeng HS, Zhang CY. Chronic inflammatory status in patients with coronary artery ectasia. Cytokine. 2009; 46: 61-4.

24. Xiao-Lin Li, Li-Feng Hong, Yan-Jun Jia, Shao-Ping Nie, Yuan-Lin Guo, Rui-Xia Xu, Cheng-Gang Zhu,Li-Xin Jiang and Jian-Jun Li Significance of red cell distribution width measurement for the patients with isolated coronary artery ectasia.Journal of Translational Medicine 2014 $12: 62 .-66$

\section{Tables}


Table 1

Baseline characters

\begin{tabular}{|c|c|c|c|c|}
\hline & Isolated Ectasia $n=24(\mathrm{~A})$ & $C A E+C A D n=112(B)$ & CAD $n=1830(C)$ & $p$ value \\
\hline Age (yrs) & $44 \pm 8.6$ & $54.32 \pm 8.72$ & $56 \pm 7.8$ & $<0.001$ \\
\hline Sex Male & $21(87.5 \%)$ & $82(73.2 \%)$ & $1318(72 \%)$ & \\
\hline Female & $3(12.5 \%)$ & $30(26.8 \%)$ & $512(28 \%)$ & \\
\hline Smoker & $15(62.5 \%)$ & $60(53.6 \%)$ & $944(51.6 \%)$ & $0.813 \mathrm{NS}$ \\
\hline Diabetes & $6(25 \%)$ & $48(42.9 \%)$ & $868(47.4 \%)$ & $<0.05$ \\
\hline SHT & $8(33.3 \%)$ & $53(47.3 \%)$ & $904(49.4 \%)$ & $0.55 \mathrm{NS}$ \\
\hline $\begin{array}{l}\text { BMI } \\
(>30 \mathrm{mg} / \mathrm{dl})\end{array}$ & $5(20.8 \%)$ & $26(23.2 \%)$ & $413(22.6 \%)$ & NS \\
\hline $\begin{array}{l}\text { LDL } \\
(>100 \mathrm{mg} / \mathrm{dl})\end{array}$ & $7(29.2 \%)$ & $41(36.6 \%)$ & $679(37.1 \%)$ & NS \\
\hline $\mathrm{HDL}(<35 \mathrm{mg} / \mathrm{dl})$ & $13(54.1 \%)$ & $51(45.5 \%)$ & $866(47.3 \%)$ & NS \\
\hline TGL (> 150 mg/dl) & $5(20.8 \%)$ & $43(38.3 \%)$ & $763(41.7 \%)$ & NS \\
\hline
\end{tabular}

Table 2

Gender Distribution

\begin{tabular}{|lllll|}
\hline & Total & Male n (\%) & Female n (\%) & M:F \\
\hline All patients & 1966 & $1421(72.3 \%)$ & $545(27.7 \%)$ & 2.6 \\
\hline Isolated Ecatsia & 24 & $21(87.5 \%)$ & $3(12.5 \%)$ & 7 \\
\hline CAE + CAD & 112 & $82(73.2 \%)$ & $30(26.8 \%)$ & 2.7 \\
\hline Total No CAE patients & 136 & $103(75.7 \%)$ & $33(24.3 \%)$ & 3.1 \\
\hline Isolated CAD & 1830 & $1318(72 \%)$ & $512(28 \%)$ & 2.52 \\
\hline
\end{tabular}

Table 3

Comparison of Traditional Risk Factors

\begin{tabular}{|lllll|}
\hline & Isolated Ectasia $\mathbf{n = 2 4}$ & CAE + CAD $\mathbf{n = 1 1 2}$ & CAD $\mathbf{n = 1 8 3 0}$ & p value \\
\hline Age $(\mathrm{yrs})$ & $44 \pm 8.6$ & $54.32 \pm 8.72$ & $56 \pm 7.8$ & $<0.001$ \\
\hline Sex Male & $21(87.5 \%)$ & $82(73.2 \%)$ & $1318(72 \%)$ & \\
\hline Female & $3(12.5 \%)$ & $30(26.8 \%)$ & $512(28 \%)$ & \\
\hline Smoker & $15(62.5 \%)$ & $60(53.6 \%)$ & $944(51.6 \%)$ & 0.013 \\
\hline Diabetes & $6(25 \%)$ & $48(42.9 \%)$ & $868(47.4 \%)$ & $<0.05$ \\
\hline SHT & $8(33.3 \%)$ & $53(47.3 \%)$ & $904(49.4 \%)$ & 0.55 NS \\
\hline BMl $(>30)$ & $25.57 \pm 3.41$ & $27.43 \pm 3.19$ & $28.15 \pm 3.56$ & $<0.001$ \\
\hline LDL & $105 \pm 22.68$ & $104.9 \pm 19.8$ & $108 \pm 16.7$ & 0.12 NS \\
\hline$(>100 \mathrm{mg} / \mathrm{dl})$ & & & & $0.136 \mathrm{NS}$ \\
\hline $\mathrm{HDL}(<35 \mathrm{mg} / \mathrm{dl})$ & $37.9 \pm-8$ & $36.19 \pm 7.13$ & $37.52 \pm 6.9$ & 0.35 NS \\
\hline TGL $(>150 \mathrm{mg} / \mathrm{dl})$ & $155.9 \pm 31.9$ & $167.17 \pm 42.99$ & $163.34 \pm 37.15$ & \\
\hline
\end{tabular}


Table 4

Comparison of Novel markers of inflammation

\begin{tabular}{|c|c|c|c|c|}
\hline & Isolated Ectasia Mean \pm SD & CAE + CAD Mean \pm SD & $\begin{array}{l}\text { Pure CAD } \\
\text { Mean } \pm \text { SD }\end{array}$ & $p$ value \\
\hline $\begin{array}{l}\text { Neutrophil } \\
\text { (cells } / \mathrm{mm}^{3} \text { ) }\end{array}$ & $5.986 \pm 1.497$ & $6.019 \pm 1030$ & $4.480 \pm 1.230$ & $<0.001$ \\
\hline Lymphocyte & $1.520 \pm 0.268$ & $1.620 \pm 0.275$ & $1.680 \pm 0.268$ & 0.011 \\
\hline NLR & $3.98 \pm 0.89$ & $3.58 \pm 0.56$ & $2.82 \pm 0.60$ & $<0.001$ \\
\hline Mean Platelet voume (MPV) & $9.94 \pm 1.56$ & $9.56 \pm 1.06$ & $9.70 \pm 1.36$ & $0.379 \mathrm{NS}$ \\
\hline Red Cell Distribution Width (RDW) & $12.59 \pm 0.60$ & $12.29 \pm 0.85$ & $12.02 \pm 0.70$ & $<0.005$ \\
\hline
\end{tabular}

\section{Figures}

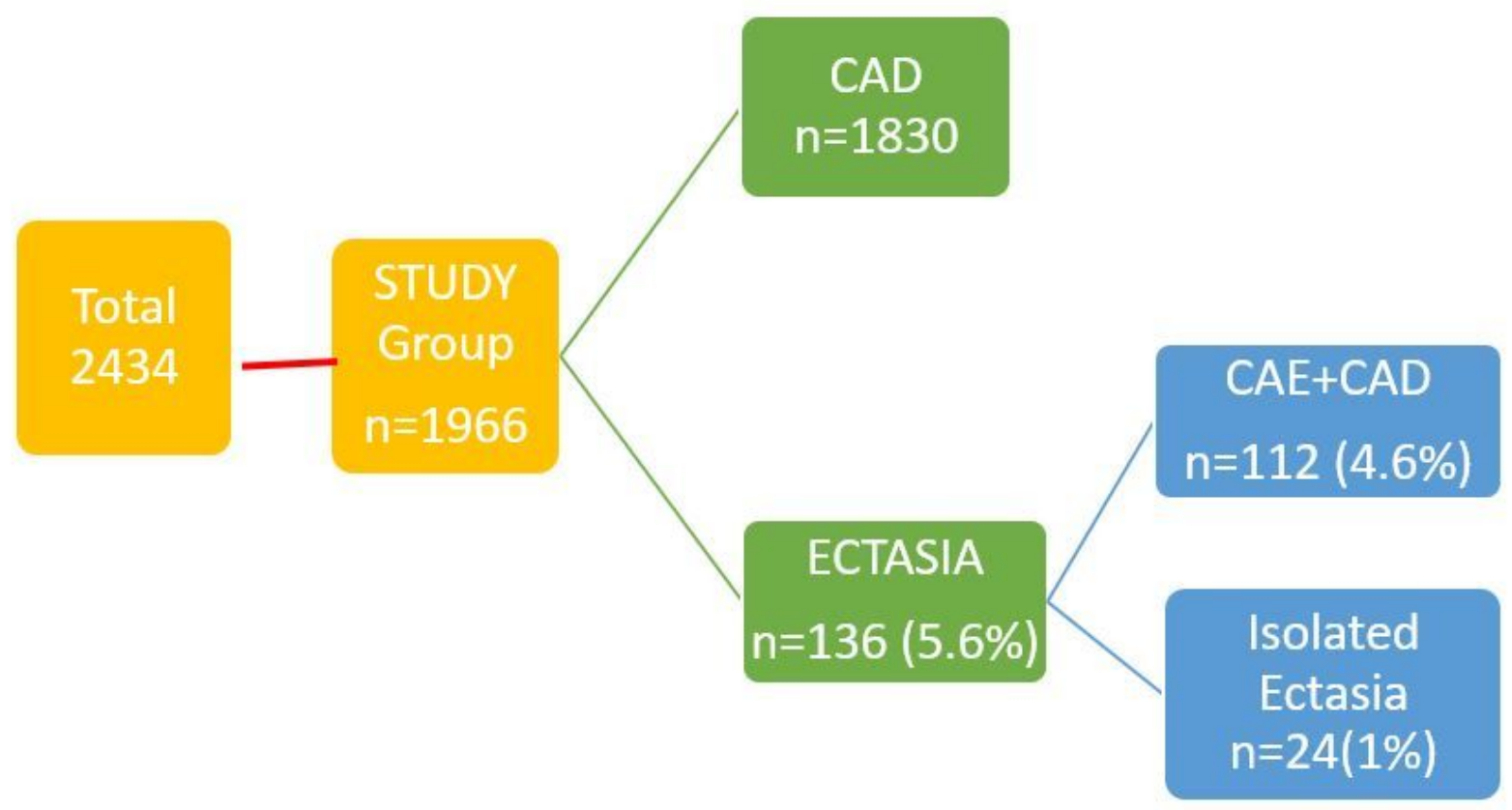

\section{Figure 1}

a: Summary of the study population 


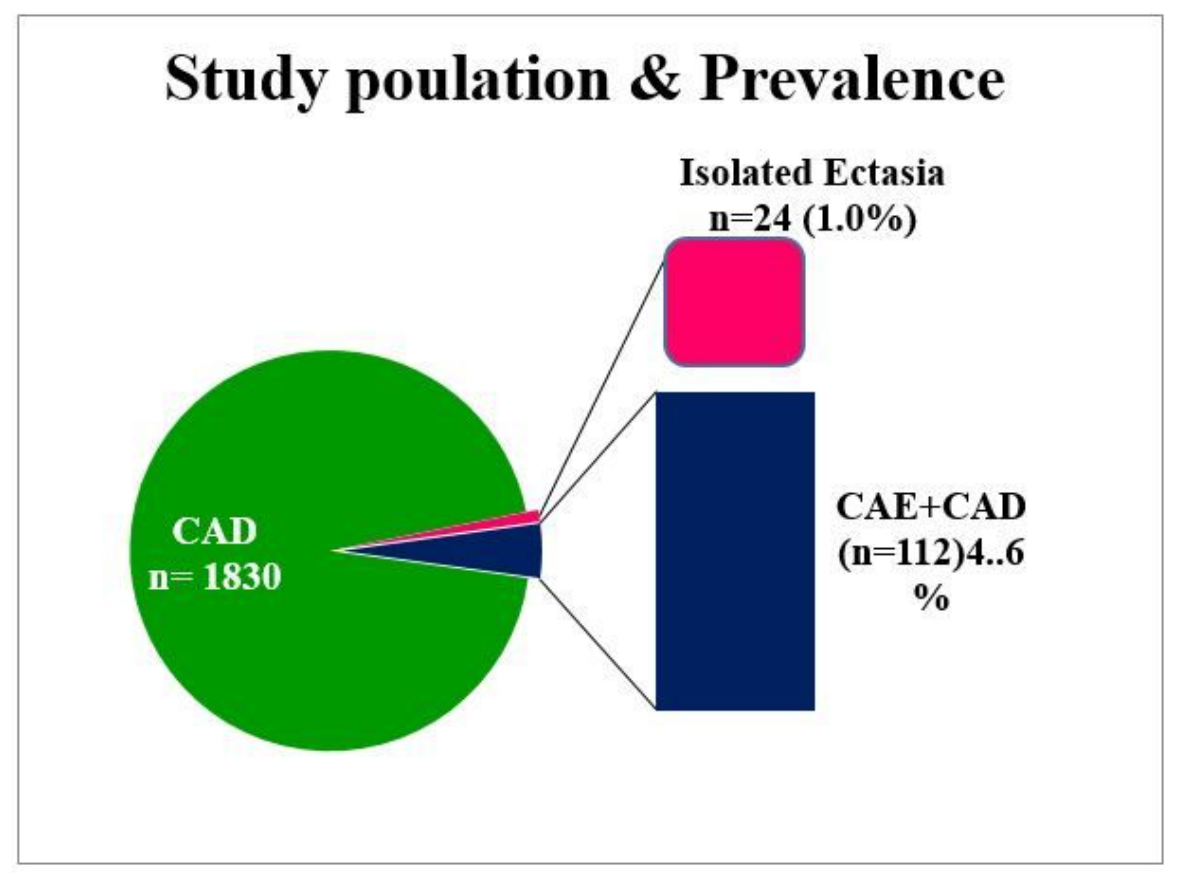

Figure 2

b: Prevalence of Ectasia

GENDER DISTRIBUTION

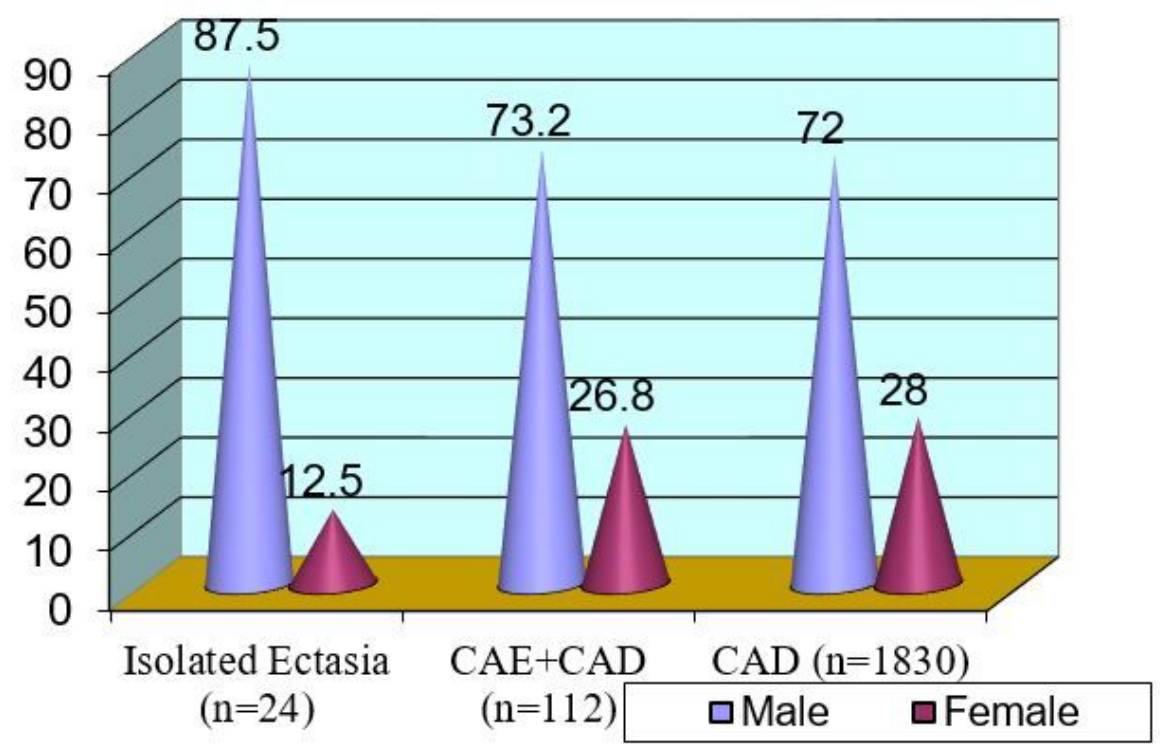

Figure 3

a: Gender Distribution 


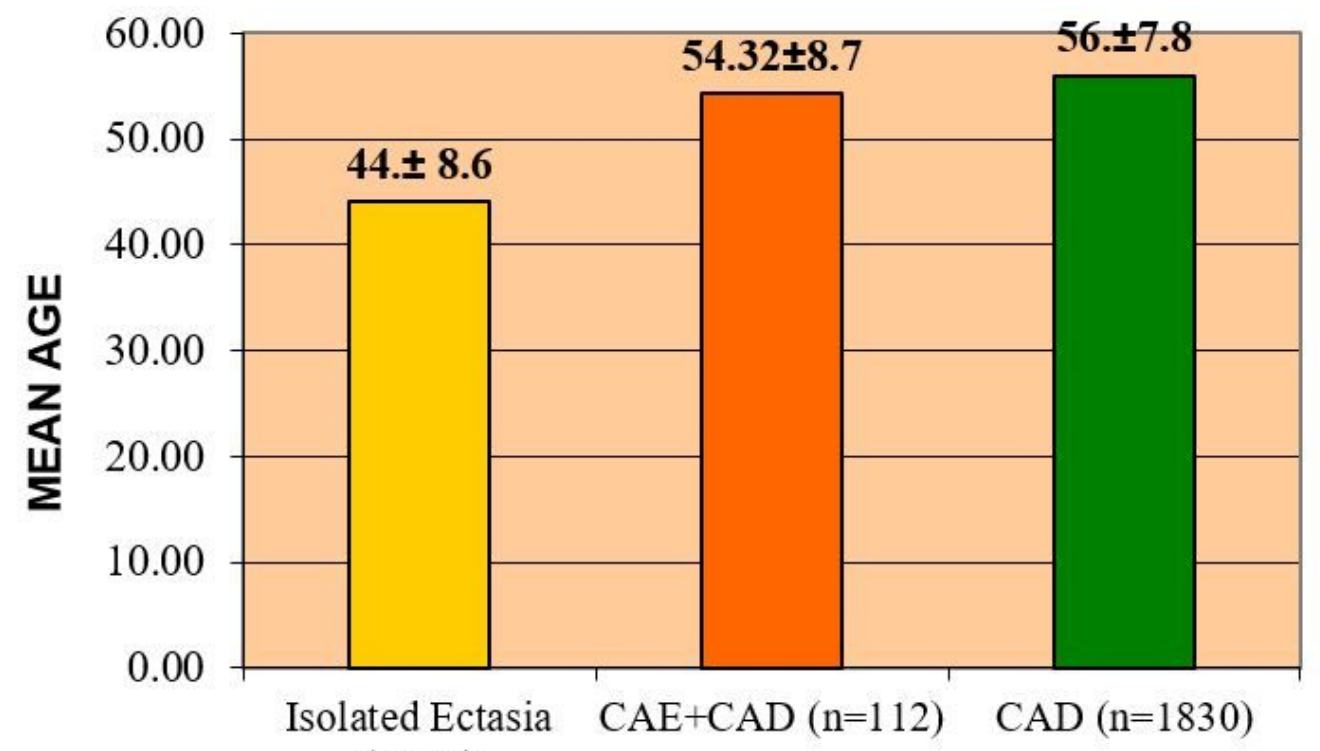

$(\mathrm{n}=24)$

口Isolated Ectasia (n=24) $\square \mathrm{CAE}+\mathrm{CAD}(\mathrm{n}=112) \quad \square \mathrm{CAD}(\mathrm{n}=1830)$

Figure 4

b: Age Distribution

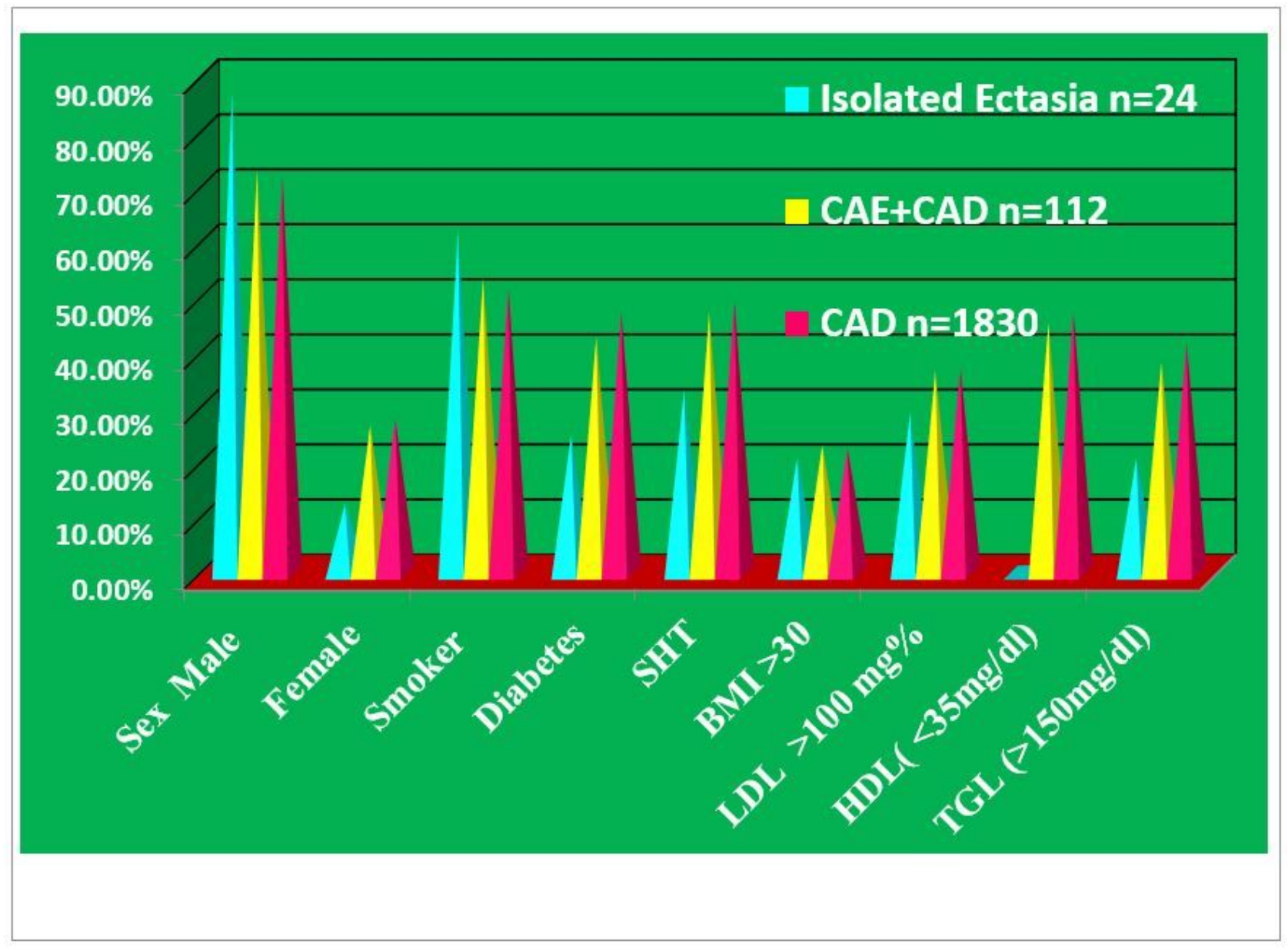

Figure 5 


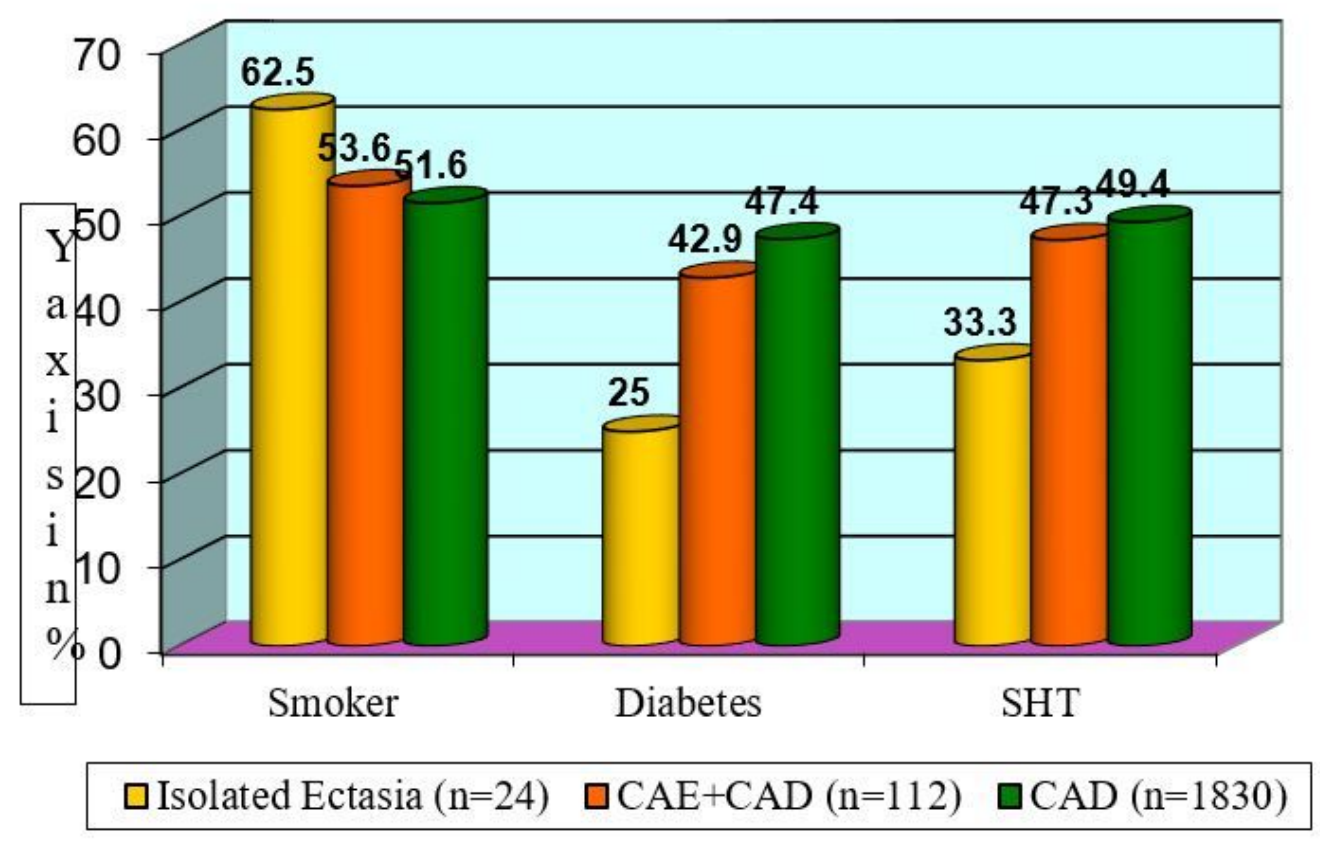

Figure 6

Comparison of traditional Risk factors

\section{Supplementary Files}

This is a list of supplementary files associated with this preprint. Click to download.

- EctasiaCL.docx

- EctasiaCL.docx 